\title{
Diagnostic yield of endomicroscopy for dysplasia in primary sclerosing cholangitis associated inflamma- tory bowel disease: a feasibility study
}

Authors

Institutions
Aldona Dlugosz ${ }^{1}$, Ammar Mohkles Barakat ${ }^{1}$, Niklas K. Björkström ${ }^{1,2}$, Åke Öst ${ }^{3}$, Annika Bergquist ${ }^{1}$

Department of Medicine Huddinge and Center for Digestive Diseases, Karolinska Institutet and Karolinska University Hospital, Stockholm, Sweden

2 Department of Medicine Huddinge and Center for Infectious Medicine, Karolinska Institutet and Karolinska University Hospital, Stockholm, Sweden

Department of Pathology Huddinge, Karolinska Institutet and Karolinska University Hospital, Stockholm, Sweden submitted

10. January 2016

accepted after revision

13. June 2016

\section{Bibliography}

DOI http://dx.doi.org/

10.1055/s-0042-111203

Published online: 5.8.2016

Endoscopy International Open

2016; 04: E901-E911

(c) Georg Thieme Verlag KG

Stuttgart · New York

E-ISSN 2196-9736

\section{Corresponding author}

\section{Aldona Dlugosz, MD, PhD}

Karolinska Institutet, Department of Medicine

Karolinska University Hospital, Huddinge

Center for Digestive Diseases

SE-14186 Stockholm

Sweden

Phone: +46858582343

Fax: +46 858582335

aldona.dlugosz@karolinska.se
Background and study aims: Primary sclerosing cholangitis associated inflammatory bowel disease (PSC-IBD) is characterized by a high risk of colorectal dysplasia. Surveillance colonoscopies with random biopsies have doubtful power for dysplasia detection. Our aim was to prospectively investigate the feasibility and efficacy of pCLE in surveillance colonoscopies in patients with PSCIBD.

Patients and methods: Sixty-nine patients with PSC-IBD underwent colonoscopy in 2 steps. On the way from rectum to cecum, the mucosa was inspected with high definition endoscopy (HDE) and random biopsies were taken according to the standard routine. On the way from cecum to rectum, fluorescein-enhanced pCLE and chromoendoscopy were performed. Regions where random biopsies had been taken, as well as visible lesions, were examined with pCLE and targeted biopsies were taken of lesions suspicious for dysplasia.

\section{Introduction \\ $\nabla$}

Patients with inflammatory bowel disease (IBD) are at increased risk for development of dysplasia and colorectal cancer (CRC). Although only $1 \%$ to $2 \%$ of patients with CRC have IBD, the cancerrelated mortality in IBD patients is approximately $15 \%[1,2]$. The risk for CRC in IBD increases with duration of colitis, early age of IBD onset, extent of colonic involvement, severity of inflammation, a family history of CRC, and in particular, concurrent primary sclerosing cholangitis (PSC) [3]. IBD patients with PSC have a 6-fold increased risk for developing dysplasia or CRC compared to non-PSC-IBD patients $[4,5]$. The cumulative risk for developing CRC in PSC-IBD patients is 33\% at 20 years and $40 \%$ at 30 years compared to $8 \%$ and $18 \%$ in IBD without concomitant liver disease $[5,6]$.
Malignancies are detected at an earlier stage in IBD patients undergoing surveillance colonos-
Two investigators, blinded to histology and endoscopy results, analyzed all pCLE videos off-line. Results: Nineteen biopsies obtained in 13 patients (17 targeted biopsies, 2 random biopsies) revealed the presence of low-grade dysplasia. Thirteen lesions with dysplasia were endoscopically visible but by using pCLE-targeted biopsies, additional endoscopically invisible dysplasias in 4 biopsies obtained from 3 patients were detected. The sensitivity, specificity, and accuracy of pCLE in predicting dysplasia were respectively $89 \%$ (95\% CI: $65-98), 96 \%$ (95\% CI: $94-97)$, and $96 \%$ (95\% CI: 94-97). pCLE showed a good performance for differentiating neoplastic from non-neoplastic mucosa with negative predictive value of $99 \%$.

Conclusions: pCLE in PSC-IBD surveillance is feasible and may be a good complement to HDE. Future research should aim at elucidating whether realtime pCLE is applicable in PSC-IBD surveillance.

copies, resulting in a better prognosis $[8,9]$. However, taking random biopsies at colonoscopy is time-consuming and the sensitivity for detection of neoplasia is insufficient [10-13]. In contrast to sporadic colorectal cancer, IBD preneoplastic tissue is often flat and multifocal and may not be appreciated in up to one-third of colonoscopies [1, $14,15]$. The dysplasia yield from surveillance colonoscopy can be improved by spraying dyes that highlight subtle changes in the architecture of the colonic mucosa. Indeed, a higher efficacy and accuracy of chromoendoscopy over conventional white light endoscopy in IBD surveillance has been confirmed [16-18]. On the other hand, narrow band imaging (NBI), which highlights vessel and crypt architecture by using blue and green light of specific wavelengths [19], has not been shown to offer any advantage over conventional colonoscopy in IBD surveillance $[19,20]$. According to the European Crohn's and Colitis Organization's (ECCO) guidelines, pan-colonic methylene 
blue or indigo carmine chromoendoscopy with targeted biopsies of any visible lesions is recommended during surveillance colonoscopy, but in centers where appropriate expertise for chromoendoscopy is not available, random biopsies (4 every $10 \mathrm{~cm}$ ) should be performed [21].

Confocal laser endomicroscopy (CLE) allows detailed evaluation of suspicious lesions at the cellular level with great detail prior to taking targeted biopsies. Two CLE systems have been developed, one of which is integrated into an endoscope (eCLE, Pentax, Tokyo, Japan) and the other is a probe confocal laser endomicroscopy (pCLE), used through the biopsy channel of the endoscope (Cellvizio, Mauna Kea Technologies, Paris, France). CLE is also often called optical biopsy because the technique offers real-time histologic images of tissue. Only a limited field of view within the mucosa can be visualized and pan-endomicroscopy of the whole colon is not feasible [22]. Therefore, macroscopic visualization of suspected areas (e.g., chromoendoscopy [red flag technique]) is useful before performing targeted CLE [23,24]. A pilot study using pCLE during colonoscopic surveillance of 22 patients with longstanding ulcerative colitis has demonstrated that this method is feasible with reasonable diagnostic accuracy [25].

PSC-IBD is suggested to represent a specific IBD phenotype characterized by extensive colitis, low inflammatory activity, right-sided colonic inflammation, and a high risk of CRC [5]. Thus, endomicroscopy-targeted biopsies might be a particularly promising method for dysplasia detection in PSC-IBD patients. However, to the best of our knowledge, pCLE together with surveillance colonoscopies has not been previously evaluated in PSC-IBD. The aim of this prospective study was to investigate the feasibility and efficacy of pCLE as a complement to high-definition endoscopy (HDE) and chromoendoscopy with random and targeted biopsy sampling for detection of colonic intraepithelial neoplasia in patients with PSC-IBD.

\section{Patients and methods}

$\nabla$

\section{Patients}

We studied patients diagnosis with PSC according to European Association for the Study of the Liver (EASL) criteria [26] and concomitant IBD who were aged 18 to 75 and previously included in an annual colonoscopy surveillance program. Exclusion criteria were pregnancy, severe concomitant diseases, clinically active IBD at the time of colonoscopy defined as Clinical Colitis Activity Index $\geq 4$ or Harvey Bradshaw Index $\geq 4[27,28]$, previous total colectomy, allergy to fluorescein, and lack of informed consent. Patients with a previous partial colectomy or liver transplantation were included if they met the inclusion criteria. Of 293 PSC patients followed at our department, 75 patients who met the inclusion and exclusion criteria were consecutively recruited between August 2011 and June 2014. Five patients declined to participate in the study and 1 patient was excluded because of insufficient quality of pCLE pictures and documentation. Of the 69 remaining patients, 48 (70\%) had been classified as having ulcerative colitis (UC), 16 (23\%) as having Crohn's Disease (CD), and $5(7 \%)$ as having unclassified IBD. For detailed patient characteristics, see Table 1.

\section{Endoscopic equipment}

Colonoscopies were performed using the Olympus EVIS EXERA II endoscopy system, incorporating HDE and NBI. Confocal endomicroscopy was performed with the probe-based system (pCLE,
Table 1 Characteristics of 69 patients with PSC-IBD included in the study.

\begin{tabular}{|lc|}
\hline Patient characteristics & \\
\hline Age, median (IQR), yr & $44(22-72)$ \\
\hline Female (\%) & $18 / 69(26)$ \\
\hline Ulcerative colitis (\%) & $48 / 69(70)$ \\
\hline Crohn colitis (\%) & $16 / 69(23)$ \\
\hline Indeterminate colitis (\%) & $5 / 69(7)$ \\
\hline IBD duration, median (IQR), yr & $19(3-64)$ \\
\hline PSC duration, median (IQR), yr & $14(1-34)$ \\
\hline Colonoscopy surveillance for more than 10 years (\%) & $42 / 69(61)$ \\
\hline Previous dysplasia in colon (\%) & $7 / 69(10)$ \\
\hline Previous colon surgery due to dysplasia & $1 / 69(1)$ \\
\hline Previous liver transplantation (\%) & $6 / 69(9)$ \\
\hline Previous or actual anti-TNF treatment (\%) & $3 / 69(4)$ \\
\hline Azathioprine and/or other immunosuppression use (\%) & $22 / 69(32)$ \\
\hline 5-ASA use (\%) & $57 / 69(83)$ \\
\hline Ursodeoxycholic acid use (\%) & $42 / 69(61)$ \\
\hline
\end{tabular}

$\mathrm{IQR}$, interquartile range; yr, years.

Cellvizio-GI, Mauna Kea Technologies, Paris, France). The laserscanning unit excites light with a wavelength of $488 \mathrm{~nm}$ via a fiberoptic mini-probe (ColoFlex type UHD; Mauna Kea Technologies). The probe (diameter $2.5 \mathrm{~mm}$ ) can be inserted through the biopsy channel of any standard colonoscope for contact with the mucosa. For tissue contrast, we used intravenous fluorescein (2.5 $\mathrm{mL}$ to $5 \mathrm{~mL}, 10 \%$ ) [29].

\section{Colonoscopy procedure}

Patients underwent colonoscopy under conscious sedation using midazolam combined with alfentanil or under sedation with propofol. All colonoscopies were performed by or under the supervision of a gastroenterologist with extensive experience in chromoendoscopy and endomicroscopy (AD) [30]. All patients were investigated in a 2-step fashion: the intubation phase and the withdrawal phase. At the intubation phase of the colonoscopy (from rectum to cecum), we performed a high-definition endoscopic (HDE) evaluation of the colon mucosa ( Fig. 1 a). The degree of inflammation was evaluated according to the Mayo Score [31] or Simple Endoscopic Score for Crohn's Disease (SES-CD) [32]. All visible lesions were assessed for size and location but not biopsied during intubation. Visible polypoid lesions within non-inflamed areas were scored according to NBI International Colorectal Endoscopic Classification (NICE) [33]. All visible lesions were prospectively classified morphologically according to Paris classification [34]. Terminology for reporting findings was modified retrospectively after the SCENIC international consensus was published [35]. Quadruple random biopsies were taken from 9 standard locations ( 3 from the right colon, 3 from the transverse colon and 3 from the left colon). This corresponded to every $10 \mathrm{~cm}$ of the colon starting from the rectum and ending at the cecum. At the withdrawal phase, after cecal intubation, fluorescein was administrated intravenously and during the withdrawal phase, all visible lesions were evaluated using chromoendoscopy with indigo carmine ( $\bullet$ Fig. 1 b). We used standard indigo carmine concentration $(0.03 \%)$ for lesion detection and in a few cases, we also used a higher concentration $(0.13 \%)$ for better lesion characterization. After HDE/chromoendosopy evaluation, each abnormal lesion was inspected using pCLE and targeted biopsies were taken whenever dysplasia was suspected on HDE/ chromoendoscopy and/or pCLE occurred. All targeted biopsies were taken on withdrawal, even from lesions detected on the 

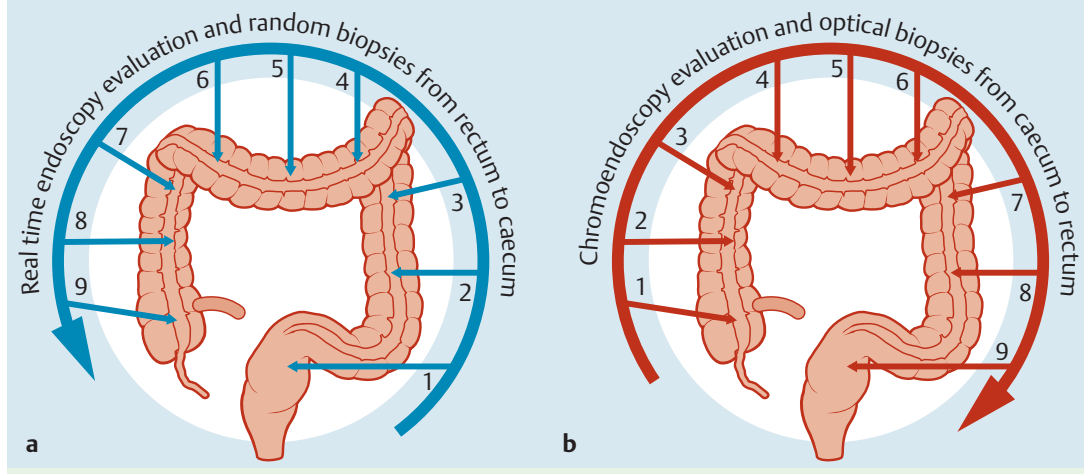

Fig. 1 Two-step colonoscopy procedure a During the intubation phase of colonoscopy (from rectum to cecum) we performed high-definition endoscopic evaluation of the colon mucosa. All visible lesions were assessed for size and location but not biopsied. Random biopsies were taken from 9 predefined locations corresponding to every $10 \mathrm{~cm}$ of the colon, starting from the rectum and ending in the cecum.

b During the withdrawal phase, all visible lesions were defined using chromoendoscopy. After HDE/ chromoendosopy evaluation, each abnormal lesion was inspected using PCLE and targeted biopsies were taken whenever a suspicion of dysplasia in HDE/chromoendoscopy and/or pCLE occurred. All areas where the random biopsies had been obtained during the intubation phase were also inspected with PCLE during the withdrawal phase.

way in. In all targeted biopsies, pCLE was performed before biopsies were taken for histology. The pCLE evaluation is referred to as "optical biopsy." We carefully examined mucosa surrounding the lesion with both HDE and pCLE but we took targeted biopsies only if HDE and/or pCLE indicated dysplasia suspicion. We did not take any additional biopsies if surrounding mucosa appeared to be normal using both methods of detection.

All areas in which random biopsies had been obtained during the intubation phase also were inspected with pCLE during the withdrawal phase and optical biopsies were performed in the adjacent region. Additional targeted biopsies for histology were taken whenever suspicious pathological real-time images were detected by pCLE. All pCLE videos were stored for future reassessment. The size, location, and endoscopic description of all visible lesions were recorded.

\section{pCLE assessment}

Evaluation of the endomicroscopy images and film sequences was done according to the recently described pCLE classification [36]. Normal crypt architecture was classified as Type 1 . Type 2 included both star-shaped luminal crypt openings and irregular size of crypts with normal or reduced number of goblet cells. Irregular, dark epithelium with tubular-shaped crypts and loss of goblet cells was classified as Type 3 [36]. For statistical analyses, classification was reduced to a dichotomous classification of non-neoplasia (crypt Type 1 and Type 2) vs. neoplasia suspicion (crypt Type 3). The pCLE images recorded during the procedure were reviewed off-line in their original format several months later. Two investigators (AD and AMB), blinded to the endoscopic and histological diagnosis, individually performed a final reassessment of the pCLE videos. After the individual assessment, a final endomicroscopic consensus judgment was obtained after discussion between the 2 investigators. Subsequently, the consensus endomicroscopy result was compared to the histopathologic diagnosis.

\section{Histopathology}

Biopsies were fixed in $4 \%$ phosphate buffered formaldehyde, embedded in paraffin and stained with hematoxylin-eosin according to routine procedures. To enhance the dysplasia diagnosis, all biopsies that showed changes suspicious for dysplasia were stained with an immunohistochemical (IHC) panel comprising monoclonal antibodies staining for p53, cytokeratin 7, cytokeratin 20 (Novocastra, Leica Microsystems, Bromma, Sweden),
P504S, and Mib-1 (Dako, Glostrup, Denmark) [37-40]. Staining was performed in a semiautomatic staining machine (Ventana ES, Ventana Medical Systems, Cedex, France) according to manufacturers protocol. The histologic evaluation, with complementary IHC when deemed necessary, was made according to the international consensus proposed by Riddell et al. [41] and the Vienna classification $[42,43]$, by gastrointestinal pathologists who were blinded to the endoscopic images. Strong overexpression for p53 and P504S, presence of overexpression for cytokeratin 7, positive staining for cytokeratin 20 in the whole crypts, and increased proliferative activity with the positive staining for Mib-1 were defined as IHC-criteria for the presence of dysplasia. All lesions with suspected dysplasia were also re-assessed by a single expert gastrointestinal pathologist (ÅÖ) to confirm the diagnosis of dysplasia.

\section{Statistics}

Descriptive statistics was used to analyze the sensitivity, specificity, and accuracy of pCLE for detecting dysplasia by comparing the assessment of optical and histopathologic biopsies taken from the same location, using histopathology diagnosis as the reference standard. To calculate sensitivity, specificity, and accuracy, a pCLE classification of 1 to 2 was considered nonneoplastic whereas a pCLE classification of 3 was considered neoplastic [36]. Interobserver agreement of the pCLE classification was calculated using the Cohen's kappa coefficient. Interpretation of kappa value was performed according to Viera and Garrett [44].

\section{Results}

This was a single-center study approved by Stockholm Regional Ethical Review Board, Stockholm, Sweden (Dnr: 2011/207-31/1). All patients invited to participate in the study signed informed consent. The study protocol has been reviewed and registered at Clinicaltrials.gov (identifier: NCT01880606).

During the intubation phase, we obtained random biopsy samples from 9 standard locations ( 3 from the right colon, 3 from the transverse colon and 3 from the left colon) in 66 patients. In 3 patients we obtained random biopsies from only 6 locations due to previous colon surgery. For further analysis we choose random biopsies taken from all locations in which the quality of corresponding pCLE sequences was good enough to compare to histopathology $(\mathrm{n}=607)$, and 37 targeted biopsies taken during withdrawal phase 


\begin{tabular}{|c|c|}
\hline Number of colonoscopies performed & 69 \\
\hline Procedures with neoplasia (\%) & $13 / 69(19)$ \\
\hline Number of biopsies containing neoplasia & 19 \\
\hline \multicolumn{2}{|l|}{ Targeted biopsies } \\
\hline $\begin{array}{l}\text { Total number of targeted biopsies } \\
\left.\text { (HDE only }{ }^{1}, \mathrm{pCLE} \text { only }{ }^{2} \text {, both } \mathrm{HDE} / \mathrm{pCLE}{ }^{3}\right)\end{array}$ & $37(13 / 7 / 17)$ \\
\hline Containing neoplasia (\%) & $17 / 37(46)$ \\
\hline All lesions identified by HDE & 30 \\
\hline Containing neoplasia (\%) & $13 / 30(43)$ \\
\hline All lesions identified by pCLE & 24 \\
\hline Containing neoplasia (\%) & $17 / 24(71)$ \\
\hline Lesions identified by both $\mathrm{HDE}$ and $\mathrm{pCLE} \mathrm{CL}^{\mathrm{C}}$ & 17 \\
\hline Containing neoplasia (\%) & $13 / 17(76)$ \\
\hline \multicolumn{2}{|l|}{ Random biopsies } \\
\hline Number of analyzed random biopsy locations & 607 \\
\hline Total number of analyzed random biopsies & 2428 \\
\hline Containing neoplasia (\%) & $2(0.08)$ \\
\hline $\begin{array}{l}\text { Number of random biopsies classified as dysplasia } \\
\text { suspicion by pCLE off-line }\end{array}$ & 17 \\
\hline Containing neoplasia (\%) & 0 \\
\hline \multicolumn{2}{|l|}{ Lesions containing neoplasia } \\
\hline Endoscopically visible lesions with LGD (\%) & $13 / 19(68)$ \\
\hline Endoscopically non-visible lesions with LGD (\%) & $6 / 19(32)$ \\
\hline HGD & 0 \\
\hline CRC & 0 \\
\hline
\end{tabular}

CRC, colorectal cancer; HDE, high definition endoscopy; HGD, high-grade dysplasia,

LGD, low-grade dysplasia; PCLE, probe-based laser endomicroscopy.

${ }^{1}$ Dysplasia suspicion only in HDE, in PCLE- no dysplasia suspicion.

2 Dysplasia suspicion only in pCLE, in HDE- no dysplasia suspicion.

${ }^{3}$ Dysplasia suspicion in both: HDE and pCLE.

( $\bullet$ Table 2). Thirteen lesions were identified by HDE/chromoendoscopy only, $17 / 37$ by both pCLE/HDE and 7/37 by pCLE only ( $\bullet$ Fig. 2). The average examination time was $54 \pm 13$ minutes (range, 30 minutes to 92 minutes).

Histopathology revealed the presence of low-grade dysplasia in 19 biopsies obtained from 13 patients (10UC, 2 CD and 1 unclassified IBD). Thirteen dysplastic lesions were endoscopically visible, 4/19 were detected by pCLE only, and 2/19 were found in random biopsies ( $\bullet$ Fig. 2). For lesions and dysplasia characteristics, see - Table 2 and Table 3. The dysplasia was localized in the right colon in 54\% (7/13) of the patients with confirmed dysplasia. Colonoscopy showed the presence of mild/moderate inflammation in $13 / 48$ patients with UC and 4/16 patients with CD. For detailed inflammation/dysplasia characteristics see $\bullet$ Table 4.

\section{HDE and dysplasia detection}

Thirty lesions (polyps or mucosa irregularities) in 16 patients were detected by HDE ( $\bullet$ Fig. 3). All visible lesions were found during the intubation phase and no additional findings were made with use of indigo carmine chromoendoscopy during the withdrawal phase. Histopathology confirmed the presence of low-grade dysplasia in 13/30 visible lesions ( $\bullet$ Table 2 and - Table 3). The sensitivity, specificity, and accuracy of HDE for detecting dysplasia were 68\% (95\% CI: 43-86), 97\% (95\% CI: 96-98), and 96\% (95\% CI: 94-97), respectively ( $\bullet$ Table 5).

\section{pCLE and dysplasia detection}

We analyzed altogether 808 pCLE sequences obtained from 644 (607 random and 37 targeted) biopsy locations in 69 patients. A total of 238280 images were studied (mean 370 images and 29 seconds per biopsy location). Each patient was investigated in a

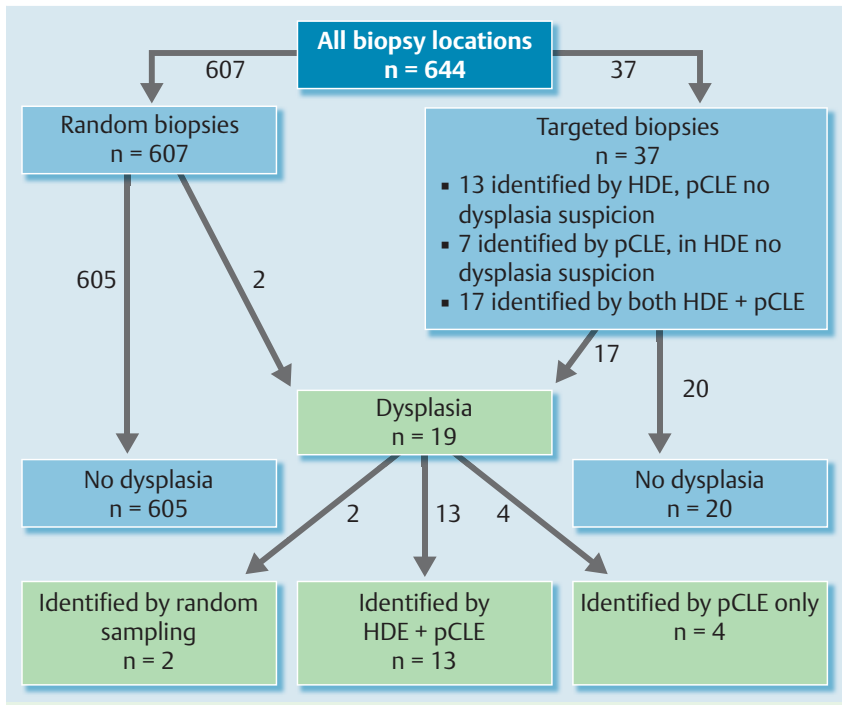

Fig.2 Flowchart showing the final histopathologic assessment of random and targeted biopsies.

HDE, high-definition endoscopy; pCLE, probe-based laser endomicroscopy; HDE-identified lesions, dysplasia suspicion only in HDE, in pCLE- no dysplasia suspicion; pCLE-identified lesions, dysplasia suspicion only in pCLE, in HDE- no dysplasia suspicion; HDE + pCLE-identified lesions, dysplasia suspicion in both: HDE and pCLE.

median of 12 sequences, which lasted an average of 4.5 minutes. Suspicion of dysplasia was found by pCLE in 41 biopsy locations in 21 patients (24 pCLE targeted biopsies and 17 random biopsy locations classified as dysplasia suspicion by pCLE off-line). Histopathology confirmed the presence of low-grade dysplasia in $17 / 41$ biopsy locations (all pCLE-targeted biopsies) ( Table 3 , - Fig.4). The sensitivity, specificity, and accuracy for dysplasia detection were 89\% (95\% CI: 65 - 98), 96\% (95\% CI: $94-97)$, and 96\% (95\% CI: 94-97), respectively ( Table 5). The interobserver agreement for pCLE classification of neoplasia versus nonneoplasia was moderate with kappa value of 0.546 (95\% CI: $0.434-$ $0.659)$

\section{Optical biopsies classified as false positive by pCLE}

Twenty-four optical biopsies from 10 patients were suspicious for dysplasia, which was not confirmed with histopathology or IHC. In 4 of the 10 patients, active inflammation in the colon was present, as noted on both endoscopy and histopathology. In the remaining 6 patients, the histopathology report described irregular epithelium that did not fulfill criteria for dysplasia $\bullet$ (Fig.5).

\section{Optical biopsies classified as false negative by pCLE}

Two of 19 biopsies were classified as false negative by pCLE. Both of these biopsies were taken randomly ( $\bullet$ Table 3 ). In the first falsenegative case, pCLE confirmed the presence of irregular epithelium without dysplasia suspicion where endoscopy showed a macroscopically normal mucosa. Histology showed irregular epithelium with discrete immunohistochemical abnormalities finally classified as a low-grade dysplasia. In the second false-negative case, real-time endoscopy showed mild inflammation (Mayo 1). pCLE showed irregular, star-shaped crypts and cellular infiltration, which was interpreted as inflammatory changes. The histopathology in that case showed foci of epithelial atypia within the inflamed area, with some of the atypical cells staining positive for 
Table 3 Characteristics of endoscopy, endomicroscopy and pathology findings of 37 targeted biopsies in 20 patients and 2 random biopsies showing the presence of low-grade dysplasia (LGD) 1 .

\begin{tabular}{|c|c|c|c|c|c|c|c|}
\hline \multirow[t]{3}{*}{ Case } & \multirow{3}{*}{$\begin{array}{l}\text { IBD } \\
\text { type }\end{array}$} & \multirow{3}{*}{$\begin{array}{l}\text { Inflammation at the } \\
\text { time of colonoscopy }\end{array}$} & \multicolumn{5}{|c|}{ Targeted biopsies (37) } \\
\hline & & & \multirow[t]{2}{*}{ Location } & \multirow[t]{2}{*}{ Endoscopic findings } & \multicolumn{2}{|l|}{ pCLE } & \multirow[t]{2}{*}{ Histopathology } \\
\hline & & & & & $\begin{array}{l}\text { Crypt } \\
\text { architecture }\end{array}$ & $\begin{array}{l}\text { Vessel } \\
\text { architecture }\end{array}$ & \\
\hline \multirow[t]{2}{*}{02} & \multirow[t]{2}{*}{ UC } & \multirow[t]{2}{*}{$\begin{array}{l}\text { Present in rectum, } \\
\text { Mayo } 1\end{array}$} & 1. Ascending colon & $\begin{array}{l}\text { Irregular surface with } \\
\text { indistinct border }\end{array}$ & 3 & 2 & Mild inflammation \\
\hline & & & 2. Ascending colon & $\begin{array}{l}\text { Irregular surface with } \\
\text { indistinct border }\end{array}$ & 3 & 2 & Mild inflammation \\
\hline \multirow[t]{4}{*}{04} & \multirow[t]{4}{*}{$C D$} & \multirow[t]{4}{*}{$\begin{array}{l}\text { Present in ascending } \\
\text { and transverse colon } \\
\text { SES-CD } 4\end{array}$} & 1. Ascending colon & $\begin{array}{l}\text { Inflamed, superficial } \\
\text { elevated surface without } \\
\text { ulcers }\end{array}$ & 3 & 3 & Active inflammation \\
\hline & & & 2. Ascending colon & $\begin{array}{l}\text { Inflamed, superficial } \\
\text { elevated surface without } \\
\text { ulcers }\end{array}$ & 3 & 3 & Active inflammation \\
\hline & & & 3. Transverse colon & $\begin{array}{l}\text { Nonpolypoid, flat lesion } \\
>10 \mathrm{~mm} \text { with indistinct } \\
\text { border, } 0 \text {-IIb }\end{array}$ & 3 & 3 & LGD \\
\hline & & & 4. Transverse colon & $\begin{array}{l}\text { Nonpolypoid, superficial } \\
\text { elevated lesion }<10 \mathrm{~mm} \text {, } \\
\text { 0-lla }\end{array}$ & 3 & 2 & LGD \\
\hline \multirow[t]{2}{*}{09} & \multirow[t]{2}{*}{$C D$} & \multirow{2}{*}{$\begin{array}{l}\text { Present in ascending, } \\
\text { transverse and } \\
\text { sigmoid colon, } \\
\text { SES-CD } 8\end{array}$} & 1. Ascending colon & $\begin{array}{l}\text { Affected surface with } \\
\text { small ulcers }\end{array}$ & 3 & 3 & $\begin{array}{l}\text { Active inflammation, } \\
\text { LGD }\end{array}$ \\
\hline & & & 2. Transverse colon & $\begin{array}{l}\text { Affected surface with } \\
\text { small ulcers }\end{array}$ & 3 & 3 & $\begin{array}{l}\text { Active inflammation, } \\
\text { LGD }\end{array}$ \\
\hline \multirow[t]{2}{*}{10} & \multirow[t]{2}{*}{ UC } & \multirow[t]{2}{*}{ Absent } & 1. Ascending colon & $\begin{array}{l}\text { Irregular surface with } \\
\text { distinct border }\end{array}$ & $2 c$ & 2 & Mild crypt irregularities \\
\hline & & & 2. Ascending colon & $\begin{array}{l}\text { Irregular surface with } \\
\text { distinct border }\end{array}$ & $2 c$ & 2 & Mild crypt irregularities \\
\hline \multirow[t]{3}{*}{12} & \multirow[t]{3}{*}{ UC } & \multirow[t]{3}{*}{ Absent } & 1. Ascending colon & $\begin{array}{l}\text { Nonpolypoid superficial } \\
\text { elevated lesion }>10 \mathrm{~mm} \\
\text { with indistinct border, } \\
0 \text {-Ila, NICE } 2\end{array}$ & 3 & 3 & $\begin{array}{l}\text { Tubular adenoma with } \\
\text { LGD }\end{array}$ \\
\hline & & & 2. Ascending colon & $\begin{array}{l}\text { Nonpolypoid superficial } \\
\text { elevated lesion }>10 \mathrm{~mm} \\
\text { with indistinct border, } \\
0 \text {-Ila, NICE } 2\end{array}$ & 3 & 3 & $\begin{array}{l}\text { Tubular adenoma with } \\
\text { LGD }\end{array}$ \\
\hline & & & 3. Transverse colon & $\begin{array}{l}\text { Polypoid sessile lesion } \\
<10 \mathrm{~mm}, 0 \text {-IIa, NICE } 1\end{array}$ & $2 c$ & 3 & Hyperplastic polyp \\
\hline \multirow[t]{3}{*}{14} & \multirow[t]{3}{*}{ UC } & \multirow[t]{3}{*}{ Absent } & 1.Descending colon & $\begin{array}{l}\text { Polypoid sessile < } 10 \mathrm{~mm} \text {, } \\
\text { Paris 0-Is, NICE } 1\end{array}$ & $2 c$ & 2 & Hyperplastic polyp \\
\hline & & & 2. Sigmoid colon & $\begin{array}{l}\text { Polypoid sessile < } 10 \mathrm{~mm} \text {, } \\
\text { Paris 0-Is, NICE } 1\end{array}$ & $2 c$ & 2 & Hyperplastic polyp \\
\hline & & & 3. Sigmoid colon & $\begin{array}{l}\text { Polypoid sessile }<10 \mathrm{~mm} \text {, } \\
\text { Paris } 0 \text {-Is, NICE } 1\end{array}$ & $2 c$ & 2 & Hyperplastic polyp \\
\hline \multirow[t]{2}{*}{16} & \multirow[t]{2}{*}{ UC } & \multirow[t]{2}{*}{ Absent } & 1. Transverse colon & $\begin{array}{l}\text { Polypoid sessile < } 10 \mathrm{~mm} \text {, } \\
\text { Paris 0-Is, NICE } 1\end{array}$ & $2 c$ & 2 & Hyperplastic polyp \\
\hline & & & 2.Descending colon & $\begin{array}{l}\text { Polypoid sessile < } 10 \mathrm{~mm} \text {, } \\
\text { Paris 0-Is, NICE } 1\end{array}$ & $2 b$ & 2 & Hyperplastic polyp \\
\hline \multirow[t]{2}{*}{20} & \multirow[t]{2}{*}{ UC } & \multirow[t]{2}{*}{$\begin{array}{l}\text { Pancolitis } \\
\text { Mayo 2, }\end{array}$} & 1.Cecum & $\begin{array}{l}\text { Absence of vascular pat- } \\
\text { tern erythema, superficial } \\
\text { elevated surface without } \\
\text { ulcers }>10 \mathrm{~mm}(0 \text {-Ila) }\end{array}$ & 3 & 3 & $\begin{array}{l}\text { Active inflammation } \\
\text { and LGD }\end{array}$ \\
\hline & & & 2. Cecum & $\begin{array}{l}\text { Absence of vascular pat- } \\
\text { tern erythema, superficial } \\
\text { elevated surface without } \\
\text { ulcers }>10 \mathrm{~mm}(0-I l a)\end{array}$ & 3 & 3 & $\begin{array}{l}\text { Active inflammation } \\
\text { and LGD }\end{array}$ \\
\hline 22 & $C D$ & Absent & 1. Ascending colon & $\begin{array}{l}\text { Polypoid sessile < } 10 \mathrm{~mm} \text {, } \\
0 \text {-Is, pit NICE } 1\end{array}$ & $2 b$ & 2 & Hyperplastic polyp \\
\hline & & & 2. Hepatic flexure & $\begin{array}{l}\text { Polypoid sessile >10 mm, } \\
0 \text {-Is, NICE } 1\end{array}$ & $2 d$ & 2 & Hyperplastic polyp \\
\hline & & & 3. Transverse colon & $\begin{array}{l}\text { Polypoid sessile < } 10 \mathrm{~mm} \text {, } \\
0 \text {-Is, NICE } 1\end{array}$ & $2 c$ & 2 & Hyperplastic polyp \\
\hline & & & 4. Splenic flexure & $\begin{array}{l}\text { Polypoid sessile < } 10 \mathrm{~mm} \text {, } \\
0 \text {-Is, NICE } 1\end{array}$ & $2 b$ & 2 & Hyperplastic polyp \\
\hline
\end{tabular}


Original aticle

\begin{tabular}{|c|c|c|c|c|c|c|c|}
\hline \multirow[t]{3}{*}{ Case } & \multirow{3}{*}{$\begin{array}{l}\text { IBD } \\
\text { type }\end{array}$} & \multirow{3}{*}{$\begin{array}{l}\text { Inflammation at the } \\
\text { time of colonoscopy }\end{array}$} & \multicolumn{5}{|l|}{ Targeted biopsies (37) } \\
\hline & & & \multirow[t]{2}{*}{ Location } & \multirow[t]{2}{*}{ Endoscopic findings } & \multicolumn{2}{|l|}{ pCLE } & \multirow[t]{2}{*}{ Histopathology } \\
\hline & & & & & $\begin{array}{l}\text { Crypt } \\
\text { architecture }\end{array}$ & $\begin{array}{l}\text { Vessel } \\
\text { architecture }\end{array}$ & \\
\hline 26 & UC & Absent & 1.Cecum & $\begin{array}{l}\text { Polypoid sessile < } 10 \mathrm{~mm} \text {, } \\
0 \text {-Is, NICE } 2\end{array}$ & 3 & 2 & $\begin{array}{l}\text { Tubular adenoma with } \\
\text { LGD }\end{array}$ \\
\hline 32 & IBD & Absent & 1. Transverse colon & $\begin{array}{l}\text { Normal mucosa } \\
\text { No visible lesion }\end{array}$ & 3 & 3 & LGD \\
\hline \multirow[t]{3}{*}{33} & UC & Absent & 1. Transverse colon & $\begin{array}{l}\text { Post-inflammatory polyp } \\
<10 \mathrm{~mm} \\
\text { Polypoid sessile ulcerated }\end{array}$ & 3 & 3 & LGD \\
\hline & & & 2. Sigmoid colon & $\begin{array}{l}\text { Post-inflammatory polyp } \\
<10 \mathrm{~mm} \\
\text { Polypoid sessile ulcerated }\end{array}$ & 3 & 3 & LGD \\
\hline & & & 3. Rectum & $\begin{array}{l}\text { Post-inflammatory polyp } \\
<10 \mathrm{~mm} \\
\text { Polypoid sessile ulcerated }\end{array}$ & 3 & 3 & LGD \\
\hline 40 & UC & $\begin{array}{l}\text { Pancolitis } \\
\text { Mayo } 1\end{array}$ & 1. Cecum & $\begin{array}{l}\text { Nonpolypoid flat lesion } \\
\text { with indistinct border } \\
>10 \mathrm{~mm}, 0 \text {-IIb }\end{array}$ & 3 & 3 & LGD \\
\hline 43 & $C D$ & Absent & 1. Transverse colon & $\begin{array}{l}\text { Post- inflammatory polyp } \\
<10 \mathrm{~mm} \\
\text { Polypoid sessile ulcerated }\end{array}$ & 3 & 3 & Mild inflammation \\
\hline 45 & UC & Absent & 1. Transverse colon & $\begin{array}{l}\text { Polypoid sessile < } 10 \mathrm{~mm} \text {, } \\
0 \text {-Is, NICE } 2\end{array}$ & 3 & 3 & $\begin{array}{l}\text { Tubular adenoma with } \\
\text { LGD }\end{array}$ \\
\hline 51 & UC & $\begin{array}{l}\text { Present in ascending } \\
\text { colon, Mayo } 1\end{array}$ & 1. Ascending colon & Honeycomb scars & 3 & 3 & LGD \\
\hline 54 & UC & $\begin{array}{l}\text { Present in cecum and } \\
\text { sigmoid colon, Mayo 1, }\end{array}$ & 1. Cecum & $\begin{array}{l}\text { Polypoid sessile < } 10 \mathrm{~mm} \text {, } \\
0 \text {-Is, NICE } 2\end{array}$ & 3 & 3 & $\begin{array}{l}\text { Tubular adenoma with } \\
\text { LGD }\end{array}$ \\
\hline 61 & $C D$ & Absent & 1. Cecum & $\begin{array}{l}\text { Irregular surface with } \\
\text { distinct border }\end{array}$ & 3 & 3 & Atypia without dysplasia \\
\hline 63 & UC & Absent & 1. Sigmoid colon & Normal mucosa & 3 & 2 & $\begin{array}{l}\text { No active inflammation, } \\
\text { no dysplasia }\end{array}$ \\
\hline \multirow[t]{2}{*}{65} & UC & Absent & 1. Descending colon & $\begin{array}{l}\text { Polypoid sessile < } 10 \mathrm{~mm} \text {, } \\
0 \text {-Is, NICE } 1\end{array}$ & $2 c$ & 3 & Hyperplastic polyp \\
\hline & & & Random biopsies (2) & & & & \\
\hline 05 & UC & Absent & 1. Ascending colon & $\begin{array}{l}\text { Normal mucosa } \\
\text { No visible lesion }\end{array}$ & $2 d$ & 2 & LGD \\
\hline 13 & UC & $\begin{array}{l}\text { Present in descending } \\
\text { and sigmoid colon, } \\
\text { Mayo } 1\end{array}$ & 1. Descending colon & $\begin{array}{l}\text { Faded vascular pattern, } \\
\text { erythema, } \\
\text { No visible lesion }\end{array}$ & $2 d$ & 2 & LGD \\
\hline
\end{tabular}

${ }^{1}$ Among targeted biopsies 13/37 were targeted with HDE, 17/37 with both HDE and pCLE and 7/37 with pCLE only. 13/30 HDE- targeted biopsies and 17/24 pCLE- targeted biopsies confirmed the presence of low-grade dysplasia (LCD). Endoscopic findings are described according to SCENIC terminology and Paris classification. NICE classification was applied only to visible polypoid lesions without concomitant inflammation. pCLE findings are described according to pCLE classification described by Kuiper et al. Crypt type 3 was assessed as dysplasia suspicion.

CD, Crohn's disease; HDE, high definition endoscopy; NICE, NBI International Colorectal Endoscopic Classification; pCLE, probe-based laser endomicroscopy; SES-CD, Simple Endoscopic Score for Crohn's Disease; UC, ulcerative colitis.

p53 and Mib-1. Final histologic assessment concluded focal atypia indefinite for low-grade dysplasia.

\section{Discussion}

$\nabla$

To the best of our knowledge, this is the first prospective study evaluating pCLE in a surveillance colonoscopy setting in PSCIBD. pCLE, as a diagnostic means for detecting dysplasia, was shown to have high sensitivity (89\%), specificity (96\%), and accu$\operatorname{racy}(96 \%)$.

These results are in line with those obtained by Kiesslich et al., who investigated eCLE in a randomized controlled trial of UC patients without concomitant PSC $(n=153)$ [45]. The aim of that study was to compare chromoendoscopy and eCLE with conventional colonoscopy with random biopsies. The authors showed that the diagnostic yield of neoplasia was increased 4.75-fold by using chromoendoscopy together with eCLE [45]. In contrast to that, Wanders et al. recently reported on the limited applicability of chromoendoscopy-guided eCLE in Crohn's colitis surveillance [46]. Although the authors achieved relatively good accuracy (87\%) and specificity (92\%) with chromoendoscopy combined with eCLE for differentiating neoplasia from nonneoplasia, they found a low incidence of dysplastic lesions. The study was terminated early because of frequent failure of the endoscopic equipment.

We chose to compare the efficacy of optical pCLE biopsies with histological biopsies to investigate whether the diagnostic yield 
Table 4 Dysplasia and inflammation detected in 69 patients with PSC-IBD.

\begin{tabular}{|c|c|}
\hline Dysplasia detected (\%) & $\mathbf{1 3 / 6 9 ( 1 9 )}$ \\
\hline UC (\%) & $10 / 48(21)$ \\
\hline In inflamed mucosa (\%) & $5 / 10(50)$ \\
\hline In non-inflamed mucosa (\%) & $5 / 10(50)$ \\
\hline CD (\%) & $2 / 16(13)$ \\
\hline In inflamed mucosa (\%) & $2 / 2(100)$ \\
\hline In non-inflamed mucosa (\%) & $0 / 2(0)$ \\
\hline Unclassified IBD (\%) & $1 / 5(20)$ \\
\hline In inflamed mucosa (\%) & $0 / 1(0)$ \\
\hline In non-inflamed mucosa & $1 / 1(100)$ \\
\hline Endoscopically visible colitis (\%) & $19 / 69(28)$ \\
\hline UC (\%) & $13 / 48(27)$ \\
\hline Mayo 1(\%) & $12 / 13(92)$ \\
\hline Mayo 2 (\%) & $1 / 13(8)$ \\
\hline CD (\%) & $4 / 16(25)$ \\
\hline SES-CD $\leq 5(\%)$ & $3 / 4(75)$ \\
\hline SES-CD $>5(\%)$ & $1 / 4(25)$ \\
\hline Unclassified IBD (\%) & $2 / 5(40)$ \\
\hline
\end{tabular}

of dysplasia detection in PSC-IBD could be increased. The high negative predictive value for dysplasia of $98 \%$ to $99 \%$ in pCLE suggests that pCLE may be a good method for excluding dysplasia without the necessity of random sampling for histology, although 2 of the optical biopsies were false negative. However, the random biopsies were sampled from normal-looking mucosa prior
Table 5 HDE and PCLE classification of dysplastic lesions.

\begin{tabular}{|lllll|}
\hline Measure & HDE & \multicolumn{3}{l}{ PCLE } \\
\hline & Fraction (\%) & $\mathbf{9 5 \% ~ C l}$ & Fraction (\%) & $\mathbf{9 5 \% ~ C l}$ \\
\hline Accuracy & $621 / 644(96)$ & $94-97$ & $618 / 644(96)$ & $94-97$ \\
\hline $\begin{array}{l}\text { Sensitivity } \\
\text { Specificity }\end{array}$ & $13 / 19(68)$ & $43-86$ & $17 / 19(89)$ & $65-98$ \\
\hline $\begin{array}{l}\text { Positive } \\
\text { predictive value }\end{array}$ & $13 / 30(43)$ & $26-62$ & $17 / 41(41)$ & $27-58$ \\
$\begin{array}{l}\text { Negative } \\
\text { predictive value }\end{array}$ & $608 / 614(99)$ & $98-100$ & $601 / 603(99)$ & $99-100$ \\
\hline
\end{tabular}

$\mathrm{Cl}$, confidence interval; HDE, high definition endoscopy; pCLE, probe-based confocal endomicroscopy.

to the acquisition of optical biopsies, and thus, it cannot be ruled out that no dysplasia remained in the mucosa when the optical biopsies were performed in the regions adjacent to where the random biopsies were taken. The false-negative cases represented indefinite or low-grade dysplasia and 1 of them was misinterpreted by pCLE as inflammatory changes.

pCLE was particularly effective in detecting dysplasia in PSC-IBD patients where no visible dysplasia suspected lesions were present. The majority of such changes were localized in the right colon, as anticipated in PSC-IBD [5]. By using pCLE as a complement to HDE, it was possible to increase the number of lesions detected. Optical biopsies from 4 locations in 3 patients revealed

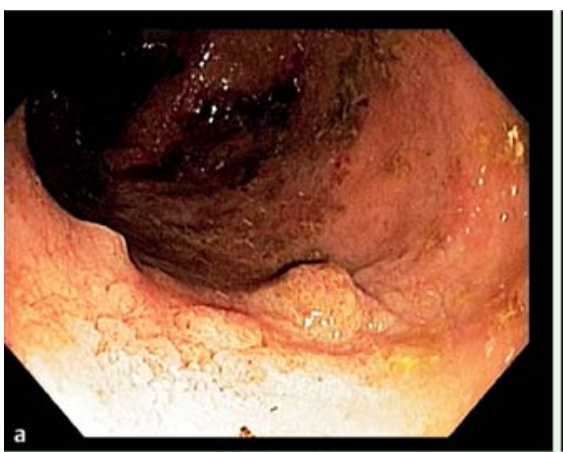

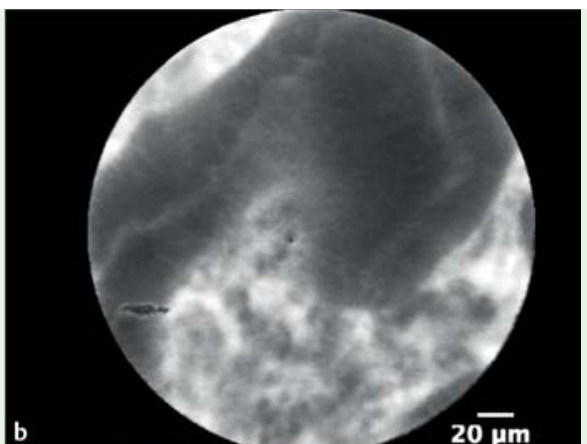

Fig. 3 Low-grade dysplasia within visible lesion in the right colon.

a Colonoscopy detected a visible lesion in the right colon. $\mathbf{b}$ and $\mathbf{c}$ PCLE showed elongated, irregular crypts with dark epithelium and fluorescein leakage. d Histopathology revealed epithelial atypia with cigar-shaped nuclei with pseudostratification, magnification 20×. e Immunohistochemistry showed stronger labeling for $\mathrm{p} 53$ in the dysplastic-appearing area than in surrounding crypts $(20 \times)$, and f extensive labeling for cytokeratin $7(40 \times)$.

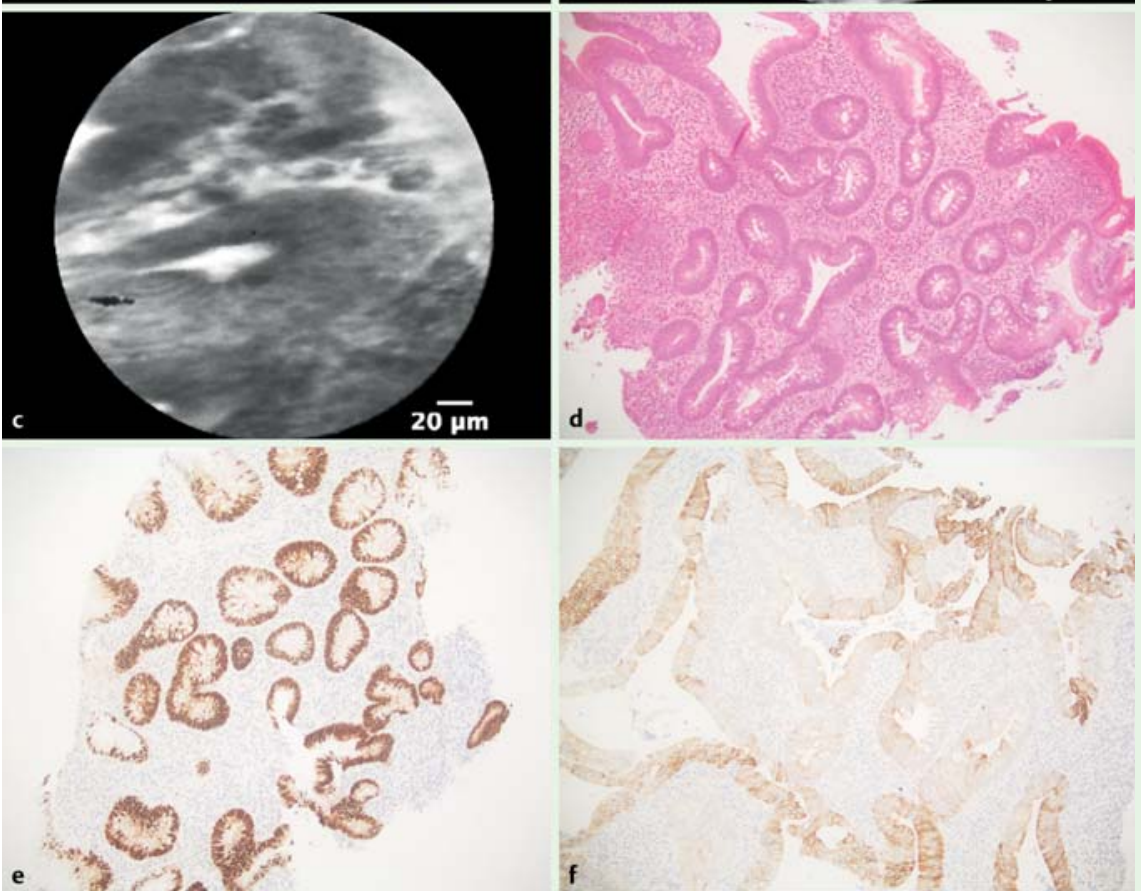



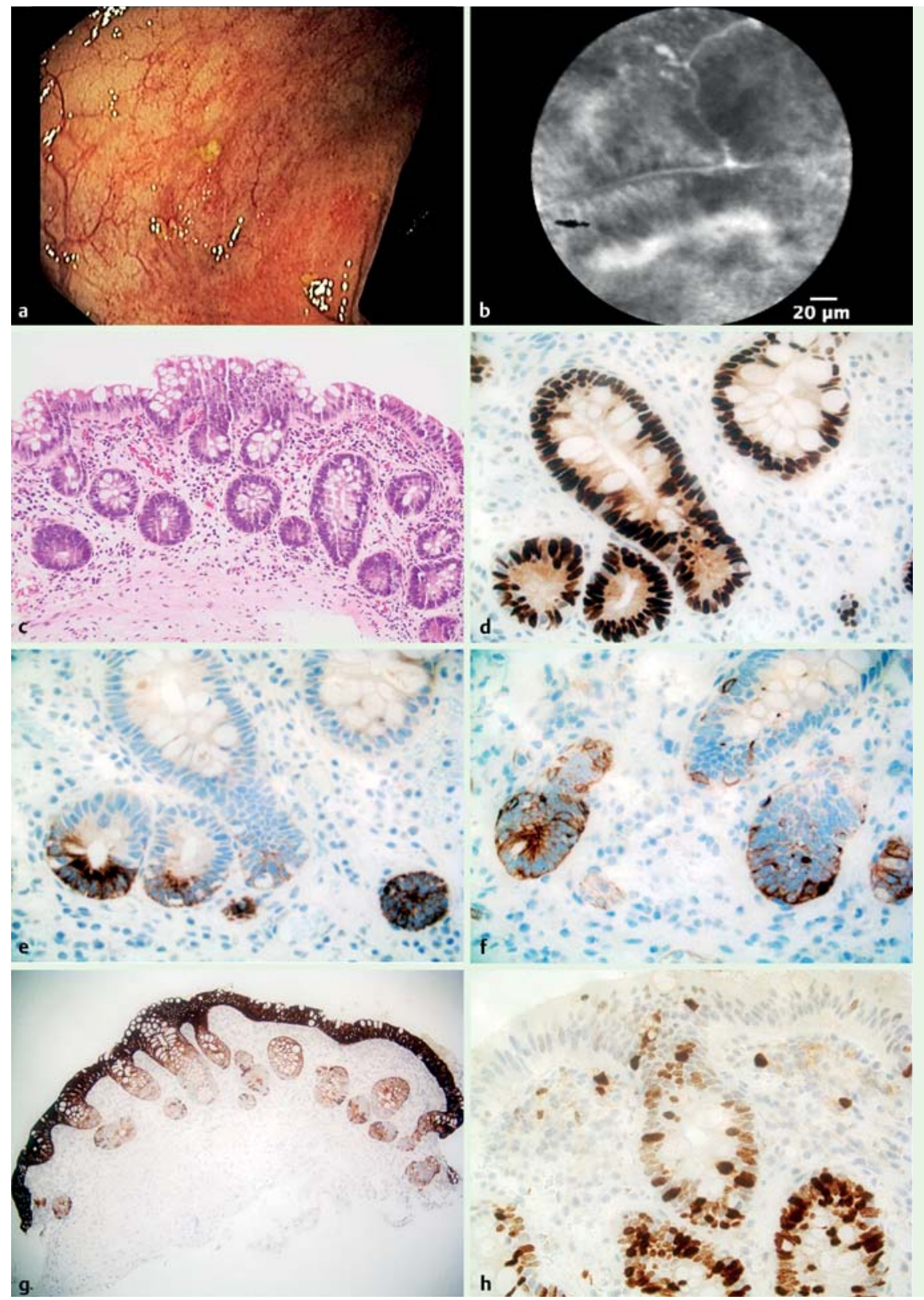

Fig.4 Low-grade dysplasia within macroscopically normal mucosa in the right colon.

a Colonoscopy showed an inactive IBD without epithelial irregularities. $\mathbf{b}$ pCLE showed irregular crypts and dark epithelium classified as a dysplasia suspicion (score 3 according to Kuiper). c Histopathology showed the presence of low-grade dysplasia in flat mucosa, magnification $20 \times$. $\mathbf{d}$ Staining for $\mathrm{p} 53$ showed strong overexpression indicating mutated p53 in the dysplastic epithelium (40×). e Staining for P405S showed an overexpression $(40 \times)$. f Staining for cytokeratin 7 showed a weak overexpression $(40 \times)$. g Staining for cytokeratin 20 was positive in whole crypts $(20 \times)$. $\mathbf{h}$ Staining for Mib-1 (Ki-67) showed an increased proliferative activity $(40 \times)$. Immunohistochemistry panel shows the presence of low-grade dysplasia suspicion for dysplasia, which was later confirmed on histopathology, whereas the mucosa was not considered dysplastic during real-time endoscopic examination. However, the number of false-positive cases also increased with use of pCLE. That was particularly true in cases in which inflammation was present. None of our patients had any symptoms of active disease and the majority (89\%) with endoscopically visible colitis had only mild inflammation, which would have been considered as mucosal healing in many studies [47].

Because mucosal inflammation in IBD is well known to reduce the accuracy of diagnosis of dysplasia, cancer surveillance should always be performed on macroscopically non-inflamed mucosa. That is also the case when using pCLE, for which we have noted that presence of inflammation, manifested by crypt destruction and fluorescein leakage, can easily be misinterpreted as dysplasia. Inflammation frequently leads to reduced goblet cells and irregular epithelium, which are also associated with dysplasia. That observation has been confirmed in other reports. In a pilot study by van den Broek et al., active inflammation was shown to be associated with the crypt type 3 appearance in as many as $18 \%$ to $22 \%$ of the cases [25]. We could probably avoid "inflammatory pitfalls" by excluding patients with visible colitis from the study analysis. However, our study did not specifically address whether presence of inflammation influenced dysplasia detection. The aim of the study was to investigate the efficacy of pCLE for detection and prediction of dysplasia. We were aware that inflammatory activity often results in mucosal irregularities that masquerade as dysplastic changes [48] and we wanted to assess if it is possible to overcome this disadvantage with real-time endomicroscopy. In our study, pCLE revealed dysplasia suspicion in 6 of 7 patients with histologically confirmed active inflammation and dysplasia at a location classified by HDE has displaying only active inflammation ( $\bullet$ Table 3 and $\bullet$ Table 4 ), but because of the study was small and therefore lacked, power firm conclusions cannot be made. Future studies should specifically address whether pCLE can make this distinction.

Our interobserver agreement for pCLE classification of neoplasia versus nonneoplasia $(0,546)$ was lower than in the study recently 

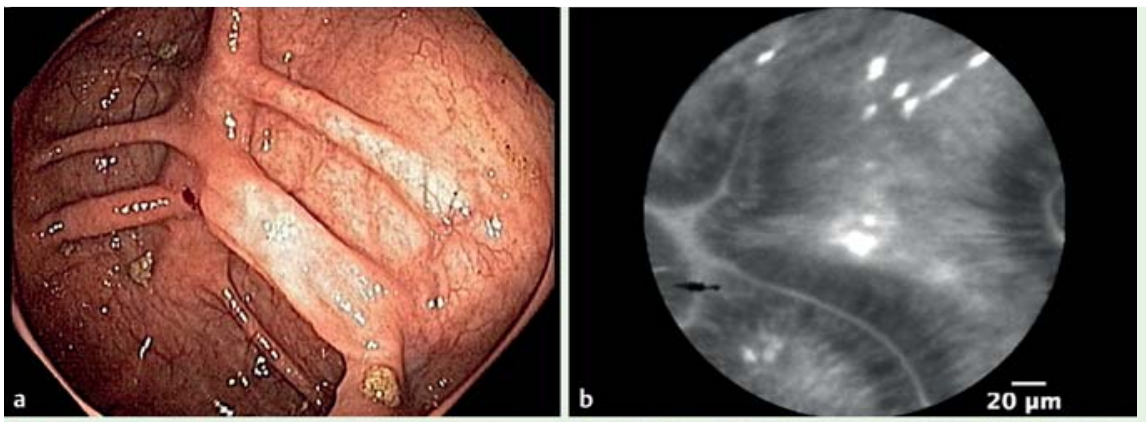

Fig.5 Epithelial atypia with increased proliferative activity but without the presence of dysplasia in the right colon mucosa.

a Colonoscopy showed an inactive IBD without epithelial irregularities. b pCLE showed elongated and irregular crypts with dark epithelium.

c Histopathology revealed epithelial atypia $(40 \times)$. d Immunohistochemistry showed weak labeling for p53 and e P405S (40×). f Mib-1 staining showed increased proliferative activity $(40 \times)$.
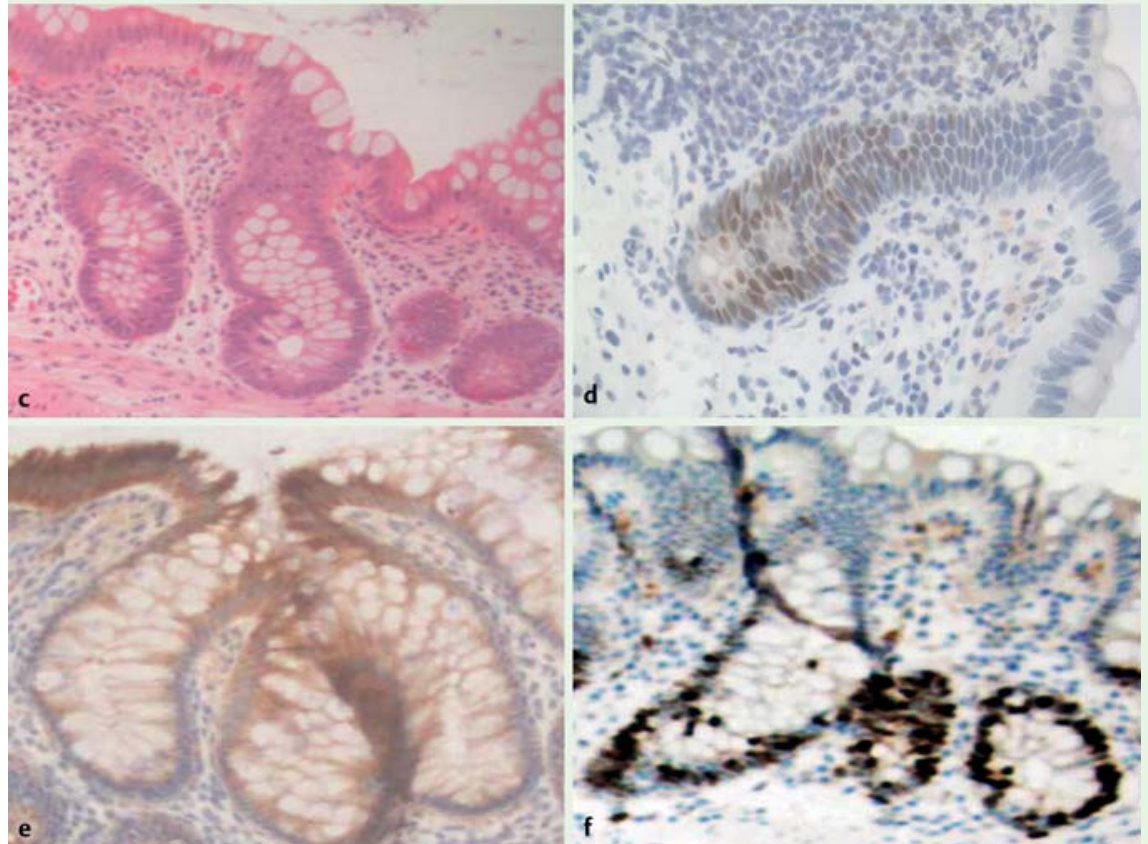

published by Hoffman et al. [49]. In that study, the kappa values for experts examining neoplasia in the colon were 0.80 and for students were 0.74 . These differences can be explained by differences in study design. In Hoffman's study, the participants analyzed 25 representative endomicroscopic images of the colon, hand-selected from the database. In our study, 2 investigators separately analyzed a large number of unselected images from 69 patients in which the quality varied. In several cases histology revealed the presence of both active inflammation and dysplasia at the biopsy location, which could easily be misinterpreted during PCLE analysis and probably influenced the obtained moderate interobserver agreement.

Based on our results, we believe that systematic random sampling with pCLE in a non-inflamed mucosa rather than random biopsies can effectively rule out dysplasia and prevent unnecessary biopsy sampling. pCLE may also be a good way to select appropriate areas for biopsies for detection of dysplastic and early neoplastic lesions in PSC-IBD. Based on our findings, it is tempting to suggest modifications of the surveillance colonoscopy protocol for PSC-IBD patients. Our results suggest that choice of endoscopic screening method should be tailored to patient risk factors. We postulate that extensive pCLE sampling, particularly in the right colon, will increase detection yield and surveillance efficiency in PSC-IBD. However, our results need to be validated by other studies, and preferably multicenter research, before that strategy is applied.

There is a consensus that surveillance and monitoring of IBD patients should be performed using a combination of red-flag tech- niques, such as chromoendoscopy or autofluorescence imaging, to screen large surfaces of mucosa for areas of interest [50]. Areas targeted with chromoendoscopy could then be further evaluated at the microscopic level, using CLE, to improve the characterization of tissue during the procedure [50]. In the study by Kiesslich et al. [45], the diagnostic yield of neoplasia was increased using chromoendoscopy with eCLE rather than conventional colonoscopy, even though the number of biopsy specimens was reduced by half [45].

We did not confirm the efficacy of the red flag technique in PSCIBD surveillance because adding chromoendoscopy or NBI did not increase the rate of detection of mucosa irregularities. Our findings are in line with results obtained by Kahi et al., who showed only marginal improvement in adenoma detection rates with the addition of chromoendoscopy to HDE [51]. In a retrospective analysis of 3242 surveillance colonoscopies, Mooiweer et al. [52] showed that despite compelling evidence from randomized trials, implementation of chromoendoscopy for IBD surveillance did not increase dysplasia detection compared with WLE with targeted and random biopsies. According to the SCENIC international consensus statement on surveillance and management of dysplasia in IBD, chromoendoscopy is suggested when performing surveillance with HDE, although this recommendation is conditional because of its reliance on only 1 relatively small observational study $[35,53]$. In our study, HDE appeared to be sufficient for detection of all visible lesions, but because our protocol of taking all random biopsies at the intubation phase resulted in longer and more careful examinations, the detection 
rate may have been higher, which may have influenced the results. We decided to put significant effort into identifying as many lesions as possible with HDE during intubation in order to concentrate on pCLE detection during withdrawal. Longer procedure duration is significantly associated with likehood of dysplasia diagnosis. In a study performed by Toruner et al. [54], every additional minute increased the rate of dysplasia diagnosis by $3.5 \%$.

We are aware that our study protocol can represent a certain degree of disadvantage. The design was chosen with the aim of acquiring both optical and histologic biopsies from the same locations in a reasonable amount of time. The timeframe for pCLE is limited after fluorescein injection. To minimize investigation time, we decided to take only targeted biopsies on withdrawal. The repeated change between pCLE probe and biopsy forceps would have prolonged the examination time in the case of random sampling on withdrawal. In that context, the choice of taking random biopsies on the way in was to make the study feasible.

All random biopsies were taken from mucosa without visible lesions. During withdrawal, we could easily identify the region where random biopsies had been taken and we took long pCLE video sequences from all regions adjacent to random biopsies. Another limitation of our study is the fact that we chose to take random biopsies from 9 predefined locations. We decided to use this description in our protocol to avoid confusion. Predefined locations were easier to follow and it helped to describe lesions for further targeted biopsies taken on withdrawal. We made notes and drawings describing lesion locations in relation to predefined biopsy locations, such as "between biopsy nr 3 and 4". Our predefined locations practically corresponded to approximately every $10 \mathrm{~cm}$ of the colon, starting from the rectum and ending at the cecum, but we realize that this description can be confusing.

\section{Conclusions \\ $\nabla$}

In conclusion, pCLE in PSC-IBD surveillance is feasible and has a high diagnostic accuracy and negative predictive value, especially in macroscopically normal mucosa and may be a good complementy to HDE. Future research should aim at elucidating whether real-time pCLE may be applicable in PSC-IBD surveillance.

\section{Competing interests: None}

\section{Acknowledgements \\ $\nabla$}

The study was supported by grants provided by the Stockholm County Council (ALF project), the Swedish Research Council, the Swedish Cancer Society and Karolinska Institutet. AD was supported by the Stockholm County Council (clinical post doctorial appointment).

\footnotetext{
References

1 Itzkowitz SH, Harpaz N. Diagnosis and management of dysplasia in patients with inflammatory bowel diseases. Gastroenterology 2004; 126: $1634-1648$

2 Vagefi PA, Longo WE. Colorectal cancer in patients with inflammatory bowel disease. Clin Colorectal Cancer 2005; 4: 313-319
}

3 Mescoli C, Albertoni L, D'Inca $R$ et al. Dysplasia in inflammatory bowel diseases. Dig Liver Dis 2013; 45: 186-194

4 Soetikno RM, Lin OS, Heidenreich PA et al. Increased risk of colorectal neoplasia in patients with primary sclerosing cholangitis and ulcerative colitis: a meta-analysis. Gastrointest Endosc 2002; 56: 48 - 54

5 Broome $U$, Bergquist A. Primary sclerosing cholangitis, inflammatory bowel disease, and colon cancer. Semin Liver Dis 2006; 26: 31 - 41

6 Mattar MC, Lough D, Pishvaian MJ et al. Current management of inflammatory bowel disease and colorectal cancer. Gastrointest Cancer Res 2011; 4: 53-61

7 Muller $A D$, Sonnenberg $A$. Prevention of colorectal cancer by flexible endoscopy and polypectomy. A case-control study of 32,702 veterans. Ann Intern Med 1995; 123: 904 - 910

8 Collins PD, Mpofu C, Watson AJ et al. Strategies for detecting colon cancer and/or dysplasia in patients with inflammatory bowel disease. Cochrane Database Syst Rev 2006. DOI: 10.1002/14651858, CD000279. pub3: CD000279

9 Itzkowitz SH, Present DH. Crohn's and Colitis Foundation of America Colon Cancer in IBD Study Group. Consensus conference: Colorectal cancer screening and surveillance in inflammatory bowel disease. Inflamm Bowel Dis 2005; 11: 314-321

10 van den Broek FJ, Stokkers PC, Reitsma JB et al. Random biopsies taken during colonoscopic surveillance of patients with longstanding ulcerative colitis: low yield and absence of clinical consequences. Am J Gastroenterol 2014; 109: 715-722

11 Rispo A, Castiglione F, Staibano $S$ et al. Diagnostic accuracy of confocal laser endomicroscopy in diagnosing dysplasia in patients affected by long-standing ulcerative colitis. World J Gastrointest Endosc 2012; 4: 414-420

12 Brostrom O, Lofberg R, Ost A et al. Cancer surveillance of patients with longstanding ulcerative colitis: a clinical, endoscopical, and histological study. Gut 1986; 27: 1408-1413

13 Blackstone MO, Riddell RH, Rogers BH et al. Dysplasia-associated lesion or mass (DALM) detected by colonoscopy in long-standing ulcerative colitis: an indication for colectomy. Gastroenterology 1981; 80: $366-$ 374

14 van Rijn JC, Reitsma JB, Stoker J et al. Polyp miss rate determined by tandem colonoscopy: a systematic review. Am J Gastroenterol 2006; 101 : $343-350$

15 Rex DK, Cutler CS, Lemmel GT et al. Colonoscopic miss rates of adenomas determined by back-to-back colonoscopies. Gastroenterology 1997; $112: 24-28$

$16 \mathrm{Wu}$ L, Li P, Wu J et al. The diagnostic accuracy of chromoendoscopy for dysplasia in ulcerative colitis: meta-analysis of six randomized controlled trials. Colorectal Dis 2012; 14: 416-420

17 Subramanian V, Mannath J, Ragunath $K$ et al. Meta-analysis: the diagnostic yield of chromoendoscopy for detecting dysplasia in patients with colonic inflammatory bowel disease. Aliment Pharmacol Ther 2011; 33: 304-312

18 Soetikno R, Subramanian V, Kaltenbach $T$ et al. The detection of nonpolypoid (flat and depressed) colorectal neoplasms in patients with inflammatory bowel disease. Gastroenterology 2013; 144: 1349-1352, 1352.e1341-1346

19 van den Broek FJ, Fockens P, van Eeden S et al. Narrow-band imaging versus high-definition endoscopy for the diagnosis of neoplasia in ulcerative colitis. Endoscopy 2011; 43: 108 - 115

20 Ignjatovic A, East JE, Subramanian Vet al. Narrow band imaging for detection of dysplasia in colitis: a randomized controlled trial. Am J Gastroenterol 2012; 107: 885-890

21 Annese V, Daperno M, Rutter MD et al. European evidence based consensus for endoscopy in inflammatory bowel disease. J Crohns Colitis 2013; 7: $982-1018$

22 Liu J, Dlugosz A, Neumann H. Beyond white light endoscopy: the role of optical biopsy in inflammatory bowel disease. World J Gastroenterol 2013; 19: $7544-7551$

23 Hoffman A, Goetz M, Vieth $M$ et al. Confocal laser endomicroscopy: technical status and current indications. Endoscopy 2006; 38: 12751283

24 Goetz $M$, Toermer T, Vieth $M$ et al. Simultaneous confocal laser endomicroscopy and chromoendoscopy with topical cresyl violet. Gastrointest Endosc 2009; 70: 959-968

25 van den Broek FJ, van Es JA, van Eeden S et al. Pilot study of probe-based confocal laser endomicroscopy during colonoscopic surveillance of patients with longstanding ulcerative colitis. Endoscopy 2011; 43: $116-122$ 
26 European Association for the Study of the Liver. EASL Clinical Practice Guidelines: management of cholestatic liver diseases. J Hepatol 2009; 51: 237-267

27 Walmsley RS, Ayres RC, Pounder RE et al. A simple clinical colitis activity index. Gut 1998; 43: 29-32

28 Harvey RF, Bradshaw JM. A simple index of Crohn's-disease activity. Lancet 1980; 1: 514

29 Wallace MB, Meining A, Canto MI et al. The safety of intravenous fluorescein for confocal laser endomicroscopy in the gastrointestinal tract. Aliment Pharmacol Ther 2010; 31: 548-552

30 Wang KK, Carr-Locke DL, Singh SK et al. Use of probe-based confocal laser endomicroscopy (pCLE) in gastrointestinal applications. A consensus report based on clinical evidence. United European Gastroenterol J 2015; 3: 230-254

31 Lewis JD, Chuai S, Nessel L et al. Use of the noninvasive components of the Mayo score to assess clinical response in ulcerative colitis. Inflamm Bowel Dis 2008; 14: 1660 - 1666

32 Daperno M, D'Haens G, Van Assche G et al. Development and validation of a new, simplified endoscopic activity score for Crohn's disease: the SES-CD. Gastrointest Endosc 2004; 60: 505-512

33 Hayashi $N$, Tanaka S, Hewett DG et al. Endoscopic prediction of deep submucosal invasive carcinoma: validation of the narrow-band imaging international colorectal endoscopic (NICE) classification. Gastrointest Endosc 2013; 78: 625-632

34 [Anonymous] The Paris endoscopic classification of superficial neoplastic lesions: esophagus, stomach, and colon: November 30 to December 1, 2002. Gastrointest Endosc 2003; 58: 3-43

35 Laine L, Kaltenbach T, Barkun A et al. SCENIC international consensus statement on surveillance and management of dysplasia in inflammatory bowel disease. Gastrointest Endosc 2015; 81: 489-501, e426

36 Kuiper T, van den Broek FJ, van Eeden $S$ et al. New classification for probe-based confocal laser endomicroscopy in the colon. Endoscopy 2011; 43: 1076-1081

37 Rodrigues NR, Rowan A, Smith ME et al. p53 mutations in colorectal cancer. Proc Natl Acad Sci USA 1990; 87: 7555 - 7559

38 Jiang Z, Fanger GR, Banner BF et al. A dietary enzyme: alpha-methylacyl-CoA racemase/P504S is overexpressed in colon carcinoma. Cancer Detect Prev 2003; 27: 422-426

39 Stenling $R$, Lindberg J, Rutegard J et al. Altered expression of CK7 and CK20 in preneoplastic and neoplastic lesions in ulcerative colitis. APMIS 2007; $115: 1219-1226$

40 Sjoqvist $U$, Ost A, Lofberg $R$. Increased expression of proliferative Ki-67 nuclear antigen is correlated with dysplastic colorectal epithelium in ulcerative colitis. Int J Colorectal Dis 1999; 14: 107-113
41 Riddell RH, Goldman H, Ransohoff DF et al. Dysplasia in inflammatory bowel disease: standardized classification with provisional clinical applications. Hum Pathol 1983; 14: 931 -968

42 Schlemper RJ, Riddell RH, Kato $Y$ et al. The Vienna classification of gastrointestinal epithelial neoplasia. Gut 2000; 47: 251 - 255

43 Rubio CA, Nesi G, Messerini $L$ et al. The Vienna classification applied to colorectal adenomas. J Gastroenterol Hepatol 2006; 21: 1697-1703

44 Viera AJ, Garrett JM. Understanding interobserver agreement: the kappa statistic. Fam Med 2005; 37: 360 - 363

45 Kiesslich R, Goetz M, Lammersdorf K et al. Chromoscopy-guided endomicroscopy increases the diagnostic yield of intraepithelial neoplasia in ulcerative colitis. Gastroenterology 2007; 132: 874-882

46 Wanders LK, Kuiper T, Kiesslich R et al. Limited applicability of chromoendoscopy-guided confocal laser endomicroscopy as daily-practice surveillance strategy in Crohn's disease. Gastrointest Endosc 2015. DOI: 10.1016/j.gie.2015.09.001

47 Mazzuoli S, Guglielmi FW, Antonelli E et al. Definition and evaluation of mucosal healing in clinical practice. Dig Liver Dis 2013; 45: 969-977

48 Thorlacius $H$, Toth $E$. Role of chromoendoscopy in colon cancer surveillance in inflammatory bowel disease. Inflamm Bowel Dis 2007; 13: 911-917

49 Hoffman A, Rey JW, Mueller L et al. Analysis of interobserver variability for endomicroscopy of the gastrointestinal tract. Dig Liver Dis 2014; 46: $140-145$

50 Leighton JA, Shen B, Baron TH et al. ASGE guideline: endoscopy in the diagnosis and treatment of inflammatory bowel disease. Gastrointest Endosc 2006; 63: 558-565

51 Kahi CJ, Anderson JC, Waxman I et al. High-definition chromocolonoscopy vs. high-definition white light colonoscopy for average-risk colorectal cancer screening. Am J Gastroenterol 2010; 105: 1301 -1307

52 Mooiweer E, van der Meulen-de Jong AE, Ponsioen CY et al. Chromoendoscopy for surveillance in inflammatory bowel disease does not increase neoplasia detection compared with conventional colonoscopy with random biopsies: results from a large retrospective study Am J Gastroenterol 2015. DOI: 10.1038/ajg.2015.63

53 Picco MF, Pasha S, Leighton JA et al. Procedure time and the determination of polypoid abnormalities with experience: implementation of a chromoendoscopy program for surveillance colonoscopy for ulcerative colitis. Inflamm Bowel Dis 2013; 19: 1913 - 1920

54 Toruner M, Harewood GC, Loftus EV et al. Endoscopic factors in the diagnosis of colorectal dysplasia in chronic inflammatory bowel disease. Inflamm Bowel Dis 2005; 11: 428-434 